\title{
FUNGAL GROWTH AND AFLATOXIN ACCUMULATION IN SYNTHETIC MEDIA CONTAINING COCONUT OIL
}

\author{
U. SAMARAJEEWA AND T. V. GAMAGE \\ Departments of Microbiology and Food Science \& Tecbnology, \\ University of Peradeniya, Peradeniya, Sri Lanka.
}

(Date of receipt : 03.06.86)

(Date of acceptance: 09.09.86)

\begin{abstract}
Toxigenic cultures of the fungus Aspergillus flavus/parasiticus were incubated in synthetic liquid and solid media containing coconut oil or its hydrolysis products as the sole source of carbon. All fungus cultures tested grew in media with coconut oil and metabolised free fatty acids. Among the different carbon sources tested, glycerol and lauric acid supported the highest growth of fungal mycelia and largest accumulation of aflatoxin B1. Capric and caproic acids were poor carbon sources for the growth of mycelia and accumulation of aflatoxin B1. The high aflatoxin B1 accumulation observed in coconut oil and its hydrolysis products, glycerol and lauric acid, explains both the high potential of grated coconut and the low potential of copra meal media for aflatoxin accumulation reported under field and laboratory conditions.
\end{abstract}

\section{Introduction}

Accumulation of the carcinogenic fungal metabolite, aflatoxin B1 in the processing and storage of food is a matter for serious concern. Of the food substrates tested for their ability to support the production of aflatoxins, grated coconut kernel was the most supportive natural substrate under laboratory conditions. ${ }^{1}$ However, growth of fungus and accumulation of aflatoxins in copra meal (poonac) were extremely rare even under high moisture conditions ${ }^{6}$ when compared with copra in which fungal growth and aflatoxin accumulation are common. ${ }^{8}$

Copra meal appears to be either deficient in a constituent necessary for fungal growth or contains an inhibitory substrate. The moisture content in coconut kernel drops from $44 \%$ to $7 \%$ on conversion to copra. The oil content in copra drops from $64 \%$ to $8 \%$, at constant moisture level, on conversion to copra meal. ${ }^{4}$ The inability of copra meal to support fungal growth and aflatoxin accumulation is therefore believed to be linked to either the absence or low levels of coconut oil in copra meal.

In this study, coconut oil and its hydrolysis products, glycerol and fatty acids, were examined for their ability to support growth of Aspergillus flavus/parasiticus and accumulate aflatoxins under laboratory conditions 
with a view to understanding the role of coconut oil in making grated coconut an excellent medium for aflatoxin accumulation.

\section{Materials and Methods}

\subsection{Cultures}

Aspergillus flavus/parasiticus cultures isolated from copra and peanuts and toxigenic strain Aspergillus parasiticus NRRL 2999 were maintained in 'Difco' Potato Dextrose Agar and 'Difco' Czapek Dox Agar at $25^{\circ} \mathrm{C}$.

\subsection{Liquid growth media (broth)}

Liquid growth media were prepared by dissolving $0.5 \mathrm{~g}$ peptone in $100 \mathrm{ml}$ tap water and mixing with $3 \mathrm{~g}$ of the relevant carbon source. The suspensions were ultrasonicated for 5 minutes and autoclaved at $121^{\circ} \mathrm{C}$ for 15 minutes in $500 \mathrm{ml}$ conical flasks. The carbon sources used were coconut oil, glycerol, capric acid, caproic acid, lauric acid,.palmitic acid and stearic acid.

\subsection{Solid growth media}

Peptone $(1 \mathrm{~g})$ was dissolved in $100 \mathrm{ml}$ of tap water and mixed with $3 \mathrm{~g}$ of carbon source. The solutions were boiled with $2 \mathrm{~g}$ agar and autoclaved at $121^{\circ} \mathrm{C}$ for 15 minutes. The media were poured into sterile petri dishes.

\subsection{Growth and toxin accumulation in broth}

Broth media $(100 \mathrm{ml})$ containing coconut oil as the sole source of carbon were inoculated in $500 \mathrm{ml}$ conical flasks with spore suspénsions $(1 \mathrm{ml})$ of Aspergillus flavus culture (Table 1 ) in $0.1 \%$ Tween 80 . The cultures were incubated static, in the dark, at room temperature $\left(25 \pm 2^{\circ} \mathrm{C}\right)$ for 11 days. The flasks were steamed for $10^{-}$minutes at atmospheric pressure.

The mycelia were separated from the broth by filtering through washed, dried and pre-weighed Whatman No.1 filter: papers. The mycelia on filter papers were washed with chloroform, dried over calcium chloride and weighed.

The free fatty acid content was estimated with $10 \mathrm{ml}$ of filtered broth by titrating against $0.1 \mathrm{~N}$ sodium hydroxide. ${ }^{5}$

The residual fat in the broth was weighed by extracting $10 \mathrm{ml}$ of broth with three $10 \mathrm{ml}$ portions of chloroform, drying in anhydrous sodium sulphate and evaporating the pooled extract to dryness. ${ }^{2}$ 
Table 1. Production of mycelia, free fatty acids and aflatoxin B1 and the residual fat observed on inoculating a synthetic broth medium with Aspergillus flavus isolates from copra and Aspergillus flavus/parasiticus NRRL 2999 followed by incubation in the dark for 11 days at $25^{\circ} \mathrm{C}$.

\begin{tabular}{|c|c|c|c|c|}
\hline $\begin{array}{l}\text { Aspergillus } \\
\text { flavus } \\
\text { isolate }\end{array}$ & $\begin{array}{l}\text { Mycelial } \\
\text { weight } \\
\text { (g) }\end{array}$ & $\begin{array}{c}\text { FFA }^{*} \\
\% \text { (as } \\
\text { lauric) }\end{array}$ & $\begin{array}{l}\text { Residual } \\
\mathrm{fat} / \mathrm{g} / 50 \mathrm{ml}\end{array}$ & $\begin{array}{c}\text { Aflatoxin B1 } \\
\mu \mathrm{g} / \mathrm{kg}\end{array}$ \\
\hline F 6 & $0.6 \%$ & 0.38 & 0.02 & N.D. \\
\hline F 7 & 0.15 & 0.40 & 0.06 & N.D. \\
\hline F 8 & 0.33 & 0.40 & 0.01 & N.D. \\
\hline F 58 & 0.13 & 0.25 & 0.03 & N.D. \\
\hline F 63 & 0.28 & 0.41 & 0.03 & N.D. \\
\hline F 73 & 0.19 & 0.25 & 0.02 & N.D. \\
\hline $\mathbf{F}, \mathrm{X}$ & 0.25 & 0.42 & 0.05 & N.D. \\
\hline NRRL 2999 & 0.02 & 0.10 & 0.05 & N.D. \\
\hline
\end{tabular}

- Initial FFA of medium was $0.02 \%$

N.D. - not detected (medium detectable level $10 \mu \mathrm{g} / \mathrm{kg}$ ).

The aflatoxin $\mathrm{B} 1$ in broth $(10 \mathrm{ml})$ was estimated by the extraction with $70 \%$ aqueous acetone and visual estimation on thin layer chromatograms. ${ }^{7}$

\subsection{Time course variation of growth}

Broth media $(100 \mathrm{ml})$ with coconut oil and without (control) as the sole source of carbon, were inoculated in $500 \mathrm{ml}$ conical flasks with spore suspensions $(1 \mathrm{ml})$ of Aspergillus parasiticus NRRL 2999 in $0.1 \%$ 'Tween 80'. The cultures were incubated static, in the dark, at room temperature $(25 \pm 2)^{\circ} \mathrm{C}$. Culture flasks in duplicate were removed at 2 day intervals, steamed for 10 minutes at atmospheric pressure and examined for mycelial growth and free fatty acid as described earlier. 
Table 2. Production of "mycelial and aflatoxin B1 by Aspergillus parasiticus NRRL 2999 inoculated into broth media containing different carbon sources and incubated static in the dark at $25^{\circ} \mathrm{C}$ for 18 days

\begin{tabular}{|c|c|c|c|c|}
\hline $\begin{array}{l}\text { carbon } \\
\text { source }\end{array}$ & $\begin{array}{l}\text { mycelial } \\
\text { weight } \\
\text { (g) }\end{array}$ & $\begin{array}{c}\text { aflatoxin B1 } \\
\mu \mathrm{g} / \mathrm{kg}\end{array}$ & $\begin{array}{c}\text { Initial } \\
\mathrm{pH}\end{array}$ & $\begin{array}{r}\text { Final } \\
\mathrm{pH}\end{array}$ \\
\hline \multirow[t]{2}{*}{ Glycerol } & 0.38 & N.D. & 6.6 & 7.4 \\
\hline & 0.14 & $\operatorname{tr}$ & 6.6 & 8.0 \\
\hline \multirow[t]{2}{*}{ Capric acid } & 0.02 & N.D. & 6.6 & 5.6 \\
\hline & 0.00 & N.D. & 6.6 & 6.5 \\
\hline \multirow[t]{2}{*}{ Caproic acid } & 0.01 & N.D. & 4.4 & 7.3 \\
\hline & 0.03 & N.D. & 4.0 & 7.1 \\
\hline \multirow[t]{2}{*}{ Lauric acid } & 0.10 & N.D. & 6.6 & 6.8 \\
\hline & 0.11 & $\mathrm{tr}$ & 6.6 & 7.9 \\
\hline \multirow[t]{2}{*}{ Pálmitic acid } & 0.07 & N.D. & 7.3 & 7.9 \\
\hline & 0.05 & N.D. & 7.3 & 8.4 \\
\hline \multirow[t]{2}{*}{ Stearic acid } & 0.10 & N.D. & 6.6 & 7.5 \\
\hline & 0.00 & N.D. & 6.6 & 8.3 \\
\hline \multirow[t]{2}{*}{ Control } & 0.12 & N.D. & 6.4 & 8.3 \\
\hline & 0.03 & N.D. & 6.4 & 6.7 \\
\hline
\end{tabular}

$\operatorname{tr}=$ traces

N.D. = not detected (minimum detectable limit $10 \mu \mathrm{g} / \mathrm{kg}$ )

\subsection{Growth of broth with different carbon sources}

Broth media $(100 \mathrm{ml})$ containing different sources of carbon as sole source (Table 2) were inoculated with spore suspensions of Aspergillus parasiticus NRRL 2999 in $0.1 \%$ 'Tween 80 '. The cultures were incubated static, in the dark, at room temperature $\left(25 \pm 2^{\circ} \mathrm{C}\right)$ for 18 days. The mycelial weight and aflatoxin accumulation in broth were estimated as described earlier. 
Table 3. Growth characteristics of Aspergillus parasiticus NRRL 2999 on solid synthetic media containing different carbon sources when incubated static in the dark at $25^{\circ} \mathrm{C}$.

\begin{tabular}{lcccc} 
carbon & & & growth on day* & \\
source & 3 & 4 & 5 & 6 \\
\hline Glycerol & + & +4 & +5 & $+6 \mathrm{~s}$ \\
Capric acid & - & - & - & - \\
Caproic acid & - & - & - & - \\
Lauric acid & + & +3 & +4 & +5 \\
Palmitic acid & - & +2 & +3 & +3 \\
Stearic acid & + & +4 & +5 & +5 \\
Ethanol & - & + & +2 & +3 \\
Glucose & + & +4 & +5 & $+6 \mathrm{~s}$ \\
Coconut meal & +2 & +4 & +5 & $+7 \mathrm{~s}$ \\
\hline
\end{tabular}

* ( $-=$ no growth; $+1=$ faint growth; $+2=0.5 \mathrm{~cm}$ thick; $+3=1 \mathrm{~cm}$ thick;

$+4=1.5 \mathrm{~cm}$ thick; $+5=70 \%$ area of medium covered with growth; $+6=90 \%$ area of medium covered with growth; $+7=$ medium totally covered with growth).

$\mathbf{s}=$ sporulated

\subsection{Growth on solid media with different carbon sources}

Agar media in petri dishes containing different sources of carbon as sole source were streaked in the middle with spores of Aspergillus parasiticus NRRL 2999 (Table 3) and Aspergillus flavus Y' (Table 4) till sporulation was observed at least with 3 carbon sources incubated at $(25 \pm 2)^{\circ} \mathrm{C}$ in the dark. Longer incubations were avoided as accumulation of aflatoxin B1 in solid cultures tend to drop after sporulation. The growth of mycelia was expressed by measuring the thickness of the streak $(+1=$ faint growth; $+2=0.5 \mathrm{~cm}$ thick; $+3=1 \mathrm{~cm}$ thick; $+5=70 \%$ of medium covered with growth; $+6=90 \%$ medium observed with growth $+7=$ medium totally covered with growth). The petri dishes were steamed for 10 minutes and the contents analysed for the presence of aflatoxins. 
Table 4. Growth characteristics and aflatoxin accumulation in synthetic solid media containing different carbon sources when incubated static with toxigenic Aspergillus flavus Y 4 at $25^{\circ} \mathrm{C}$ in dark

\begin{tabular}{lcccc}
\hline & & \multicolumn{2}{c}{ growth on day } & $\begin{array}{c}\text { aflatoxin B1 } \\
\mu \mathrm{g} / \mathrm{kg}\end{array}$ \\
\cline { 2 - 5 } & 2 & 5 & 10 & \\
\hline Glycerol & +3 & +4 & $+5 \mathrm{~s}$ & 110 \\
Lauric acid & +1 & +1 & $+2 \mathrm{~s}$ & 88 \\
Palmitic acid & +2 & +3 & $+4 \mathrm{~s}$ & 38 \\
Glucose (control) & +4 & +5 & $+6 \mathrm{~s}$ & 88 \\
\hline
\end{tabular}

s- sporulated

+1 to +6 same as in Table 3

\section{Results and Discussion}

\subsection{Growth of fungi in coconut oil}

All fungi tested grew in the broth media containing coconut oil as the sole source of carbon (Table 1). This is in contrast to what was reported with copra meal (poonac) where there was no growth of fungi under experimental conditions. ${ }^{6}$ The increase of free fatty acid content (FFA) observed indicated that lipolysis occurred along with growth of fungi although aflatoxin accumulation and lipolysis by Aspergillus flavus are not related to each other. ${ }^{9}$. The varying pattern of FFA observed with time course suggested that the fatty acids were probably being assimilated by the fungi as they were produced during lipolysis (Figure 1).

The low residual fat content observed in the media strongly suggested that the coconut oil was being assimilated by the fungi during their growth. This possibility was further supported by the high mycelial weight observed in broth media containing coconut oil (Figure 1). 


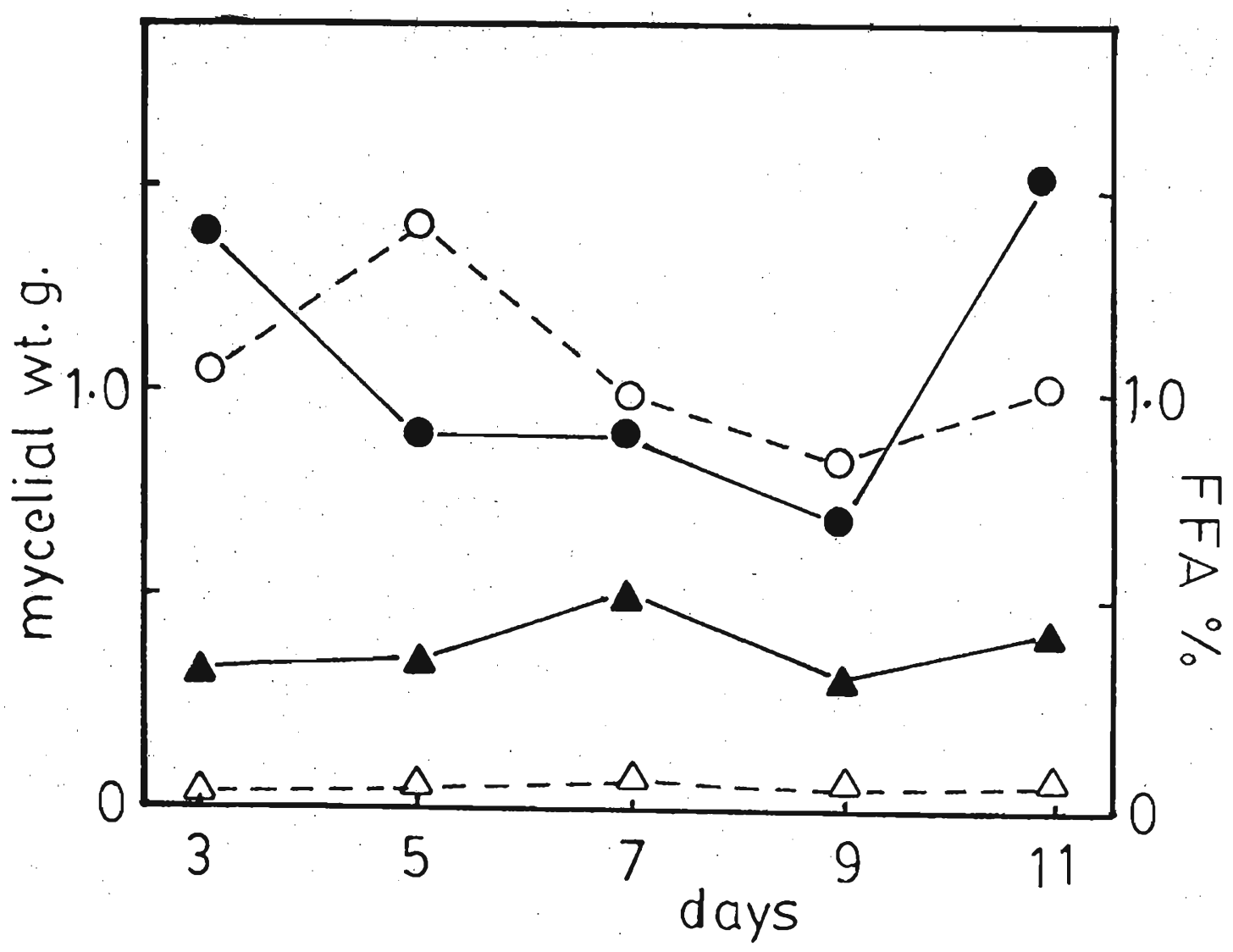

Figure 1. Time course variation in growth and tree fatty acid production in the presence and absence of coconut oil in synthetic broth media by Aspergillus parasiticus NRRL 2999 when incubated at $25^{\circ} \mathrm{C}$.

Free fatty acid - presence of coconut oil absence of coconut oil 0

Mycelial weight - presence of coconut oil $\Delta$ absence of coconut oil + 


\subsection{Fungal growth in hydrolysis products of coconut oil}

Of the different hydrolysis products of coconut oil tested (Table 2) glycerol appeared to be the prime source of carbon for mycelial growth. Arseculeratne $e t a l^{1}$ speculated that the high aflatoxin producing/accumulating ability of grated coconut was because of the higher concentration of glycerol available from it.

Of the fatty acids tested lauric acid showed the highest potential for mycelial growth and accumulation of aflatoxins and palmitic acid was next. Gupta $e t \mathrm{al}^{3}$ also have observed the high potential of lauric acid to support aflatoxin production. Among the edible oils coconut oil is rich in lauric acid, palmitic acid and glycerol: This may be one of the factors for the high aflatoxin producing potential of grated coconut when compared with other natural substrates.

The inability of capric and caproic acids to support fungal growth and aflatoxin accumulation was noted both in liquid (Table 2) and solid (Table 3) media. These acids are present in low concentrations in coconut oil. However, the increase in $\mathrm{pH}$ observed in the media (Table 2) showed that the acids are assimilated even to a small extent during the growth of fungi.

\subsection{Aflatoxin accumulation}

At times, very low or no aflatoxin accumulation occurs in liquid media. However, traces of aflatoxin B 1 were observed only with glycerol and lauric acid when tested in liquid media with a highly toxigenic Aspergillus culture (Table 2). Enhanced accumulation of aflatoxins was noted in' solid media with glycerol and lauric acid (Table 4). Although glucose induced a better growth of mycelia than glycerol and lauric acids aflatoxin production in glycerol and lauric acid was much higher than in glucose in relation to mycelial growth.

\section{Conclusion}

The observations from these experiments help to explain the paradox of grated coconut being an excellent medium for aflatoxin accumulation whereas copra meal is not. The vital difference is the absence in copra meal of a high concentration of coconut oil which on hydrolysis produces glycerol and lauric acid sufficient to support fungal growth and aflatoxin accumulation in grated coconut. 


\section{Acknowledgements}

This work was supported by the research grant RG/83/27 of the Natural Resources, Energy and Science Authority of Sri Lanka.

\section{References}

1. ARSECULERATNE," S.N., SILVA, DE L.M., WIJESUNDERA, S. \& BANDUNATHA, C.H.S.R. (1969) Appl. Microbiol., 18 : 88-94.

2. CORNELIUS, J.A., EGGINS, H.O.W. \& WALLBRIDGE, A. (1984) Biodeterioration of Palm oil constituents caused by fungi. Personnel communication.

3. GUPTA, S.R., PRASANNA, M.R., WISWANATHAN, L. \& VENKITASUBRAMANIAM, T.A. (1974) Experimentia 30 : 1244-1246.

4. MENON, K.P.V. \& PANDALAI, K.M. (1958) The coconut palm, India Central Coconut Committee, S. India.

5. PEARSON, D. (1976) The Chemical Analysis of Foods, Seventh edition, Chemical publishing Co. Inc., New York. p. 597.

6. SAMARAJEewA, U. (1975) Ph.D. thesis, University of Sri Lanka, Peradeniya.

7. SAMARAJEeWA, U. \& ARSECULERATNE, S.N. (1975) J. Food Sci. Tecbnol., $12: 27-31$.

8. SAMARAJEEWA, U. \& ARSECULERATNE, S.N. (1983) J. Natn. Sci.Coun. Sri.Lanka, $11: 225-235$.

9. SAMARAJEEWA, U., GAMAGE, T.V. \& ARSECULERATNE, S:N. (1983) J. Natn. Sci. Coun. Sri Lanka 11 : 203-210. 